\title{
Echocardiographic assessment of the right ventricle in COVID-19: a systematic review
}

\author{
Simone Ghidini ${ }^{1,2} \cdot$ Alessio Gasperetti $^{3} \cdot$ Dario Winterton $^{4,5} \cdot$ Marco Vicenzi $^{1,2} \cdot$ Mattia Busana $^{6}$. \\ Giovanni Pedrazzini $^{7,8} \cdot$ Luigi Biasco $^{7,9} \cdot$ Gregorio Tersalvi $^{8,10}$
}

Received: 23 May 2021 / Accepted: 16 July 2021 / Published online: 22 July 2021

(c) The Author(s), under exclusive licence to Springer Nature B.V. 2021

\begin{abstract}
Cardiac involvement has been frequently reported in COVID-19 as responsible of increased morbidity and mortality. Given the importance of right heart function in acute and chronic respiratory diseases, its assessment in SARS-CoV-2 infected patients may add prognostic accuracy. Transthoracic echocardiography has been proposed to early predict myocardial injury and risk of death in hospitalized patients. This systematic review presents the up-to-date sum of literature regarding right ventricle ultrasound assessment. We evaluated commonly used echocardiographic parameters to assess RV function and discussed their relationship with pathophysiological mechanisms involved in COVID-19. We searched Medline and Embase for studies that used transthoracic echocardiography for right ventricle assessment in patients with COVID-19.
\end{abstract}

Keywords SARS-CoV-2 $\cdot$ Echocardiography $\cdot$ Right ventricle $\cdot$ Pulmonary hypertension

\section{Introduction}

Coronavirus disease 2019 (COVID-19) is a systemic viral disease with predominantly respiratory clinical presentations leading to multi-organ complications and fatal outcomes. In particular, cardiac involvement and myocardial injury (defined as a rise in cardiac troponin) have been frequently reported as a consequence of COVID-19 [1, 2] and their

Simone Ghidini and Alessio Gasperetti contributed equally as first authors to this work.

Luigi Biasco and Gregorio Tersalvi contributed equally as senior authors to this work.

Gregorio Tersalvi

tersalvi@gmail.com

1 Cardiovascular Disease Unit, Fondazione IRCCS Ca' Granda Ospedale Maggiore Policlinico, Milan, Italy

2 Dyspnea Lab, Department of Clinical Sciences and Community Health, University of Milan, Milan, Italy

3 Division of Cardiology, Department of Medicine, Johns Hopkins University, Baltimore, MD, USA

4 Department of Anesthesia and Intensive Care Medicine, Niguarda Ca' Granda, Milan, Italy

5 Department of Medicine and Surgery, University of Milan-Bicocca, Monza, Italy presence is associated to increased morbidity and mortality $[3,4]$.

Research efforts have focused on the identification of easy-to-use biological markers of myocardial injury with high predictive accuracy for in-hospital events [5-8]. Despite those efforts, several pathophysiological mechanisms of cardiac involvement in COVID-19 are still ambiguous and need to be fully clarified. Preliminary data suggested that cardiac imaging studies can be useful as predictive tools, as well as to understand underlying mechanisms of cardiac involvement [9-12].

Given the clinical relevance of the right heart function in respiratory illness and acute respiratory distress syndrome

6 Department of Anesthesiology, University Medical Center Göttingen, Göttingen, Germany

7 Department of Biomedical Sciences, University of Italian Switzerland, Lugano, Switzerland

8 Division of Cardiology, Cardiocentro Ticino Institute, Lugano, Switzerland

9 Division of Cardiology, Azienda Sanitaria Locale Torino 4, Ospedale di Ciriè, Ciriè, Italy

10 Department of Internal Medicine, Hirslanden Klinik St. Anna, Sankt-Anna-Strasse 32, 6006 Lucerne, Switzerland 
(ARDS), [13-16] transthoracic echocardiography (TTE) of the right ventricle (RV) may be crucial in evaluating patients with COVID-19, as suggested by European Association of Cardiovascular Imaging (EACVI) and American Society of Echocardiography (ASE) recommendations [17, 18].

The aim of this systematic review is to summarize current knowledge on TTE-based RV assessment in COVID-19, focusing on the pathological mechanisms behind right chambers involvement, the parameters for prognostic assessment, and the clinical utility of TTE parameters in the trajectory of this disease.

\section{Methods}

\section{Search strategy and study selection}

This systematic review has been performed and reported in accordance with the Preferred Reporting Items for Systematic Reviews and Meta-Analyses (PRISMA) guidelines [19].

We conducted a comprehensive search of Medline (through PubMed) and Embase until April 30th, 2021. The following search terms were used:

(heart OR cardiac OR ventric* OR cardiovasc *) AND (dysfunction OR enlargement OR reduc* OR impairment OR injury OR dilation OR failure OR involvement OR remodeling OR pulmonary hypertension) AND right AND ('COVID 19' OR COVID19 OR 'novel coronavirus' OR 'SARS CoV 2').

After the primary search duplicates were removed. The obtained cohort were firstly screened by title by 2 independent reviewers (S.G, A.G.). Therefore, a subsequent control was performed through assessment of abstracts. All eligible studies were read in full, to control suitability for review inclusion. References of included manuscript were screened for the identification of potential additional studies of interest. Consensus of the 2 reviewers was needed for a study inclusion. A third reviewer (G.T.) served as final judge in cases of divergence between the 2 reviewers.

\section{Inclusion and exclusion criteria}

Inclusion criteria were:

- All adult patients (>18 years) hospitalized for COVID19 ;

- Studies reporting RV assessment using TTE;

- Randomized controlled trials, cohort and case-control studies;

- English language;

- Available as a full manuscript at the time of the literature search.
Exclusion criteria were:

- Case reports;

- Systematic or narrative reviews;

- Pediatric studies;

- Studies not reporting appropriate descriptors and outcomes;

- Studies not available as a full manuscript.

\section{Data extraction}

Two independent investigators (S.G., A.G.) performed data extraction. To facilitate data extraction, a standardized extraction form was used, retrieving the following study characteristics: study design; number of patients enrolled; outcomes (defined as invasive mechanical ventilation [IMV], in-hospital death), and TTE parameters of interest (where available): left ventricular ejection fraction (LVEF) and global longitudinal strain (GLS) for Left Ventricle (LV); $\mathrm{RV}$ end diastolic diameter (RVEDD), RV end diastolic area (RVEDA) RV fractional area change (RVFAC), RV free wall longitudinal strain (RVLS), tricuspidal Anulus Plane Systolic Excursion (TAPSE), tricuspidal regurgitation peak velocity (TRV), tricuspid lateral annular systolic velocity (S'), pulmonary hypertension $(\mathrm{PH})$, systolic pulmonary artery pressure (sPAP), inferior vena cava diameter and distensibility for RV.

\section{Results}

\section{Search results}

The study selection process is presented in Fig. 1. Out of a total of 795 initial results, 193 remained after removing duplicates, papers written in languages other than English, reviews, editorials, letters, and case reports. Of these, 78 were chosen based on title relevance for additional analysis of the abstracts, and 52 were designated for further analysis of the full text paper in which 7 works were excluded. Quality assessment did not reject any study. Fourty-five papers were therefore considered suitable for inclusion. No other published work was added after re-examining its reference lists. The systematic review finally included a total of 45 studies, which are presented in Table 1.

\section{Right ventricular dilatation}

Since RV size measurements are easy and quick to perform, many studies reported parameters of RV dilatation in COVID-19. The most frequent dimension reported is the $\mathrm{RV}$ end-diastolic diameter (RVEDD), measured at the RV base in apical 4-chamber projection [65]. It is demonstrated 
Fig. 1 Flowchart for the study selection process
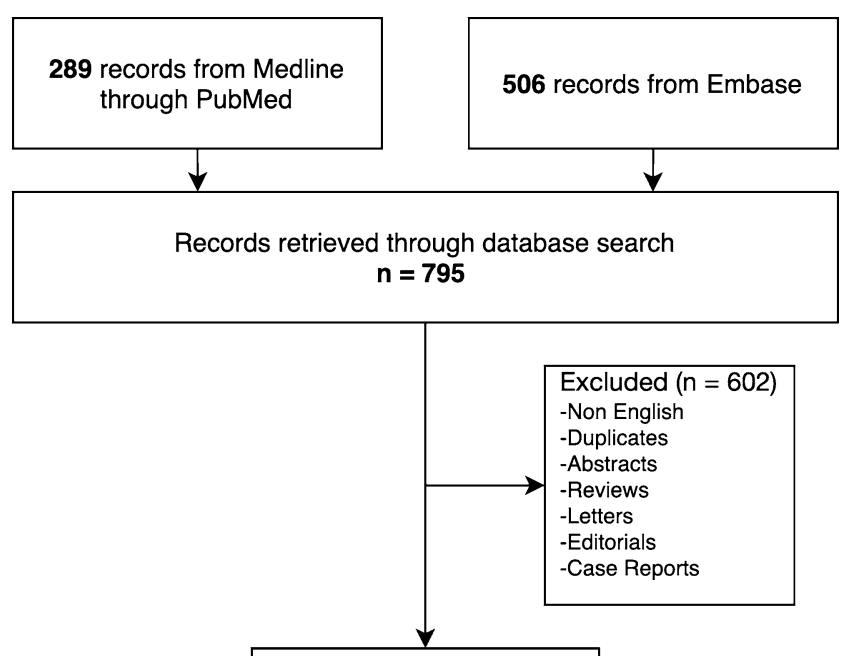

English full-text research articles $n=193$

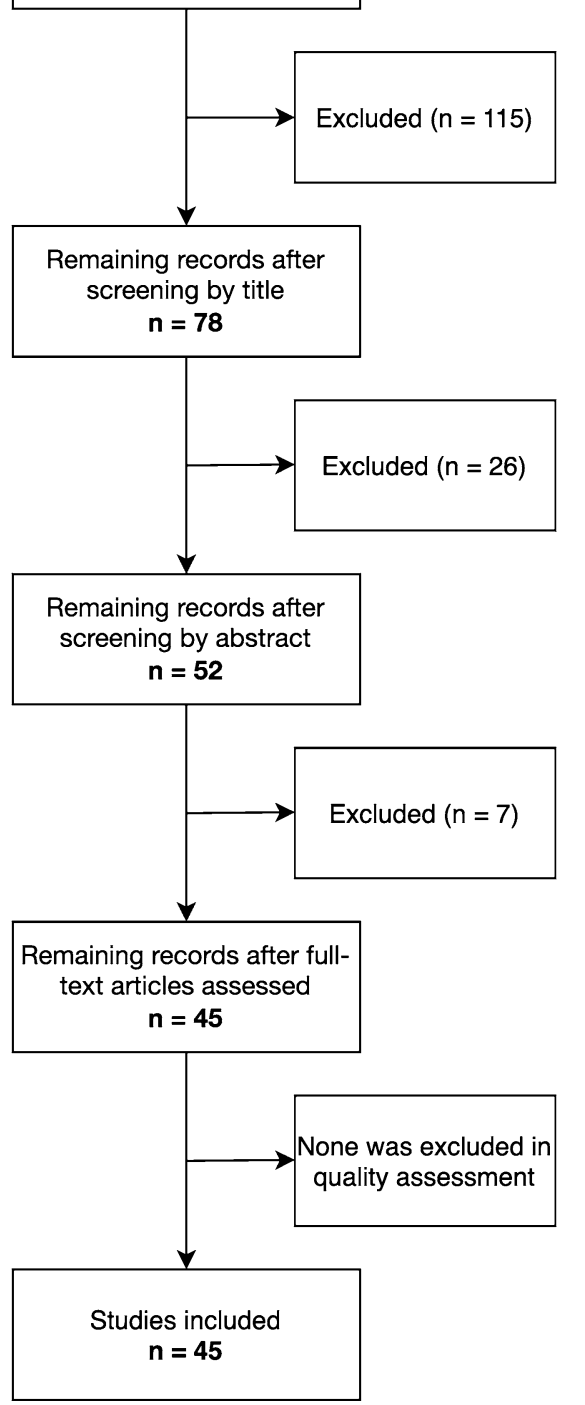




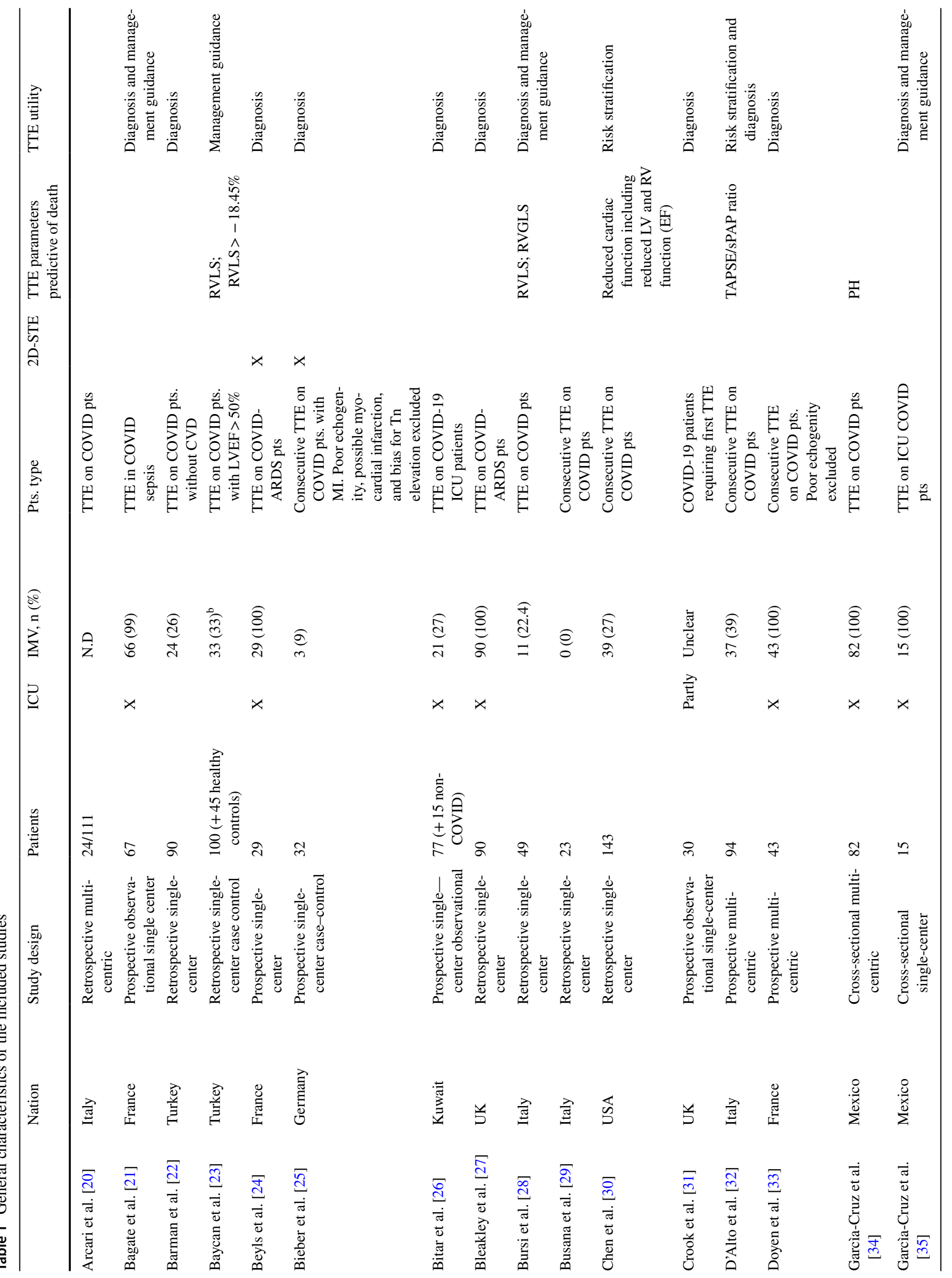




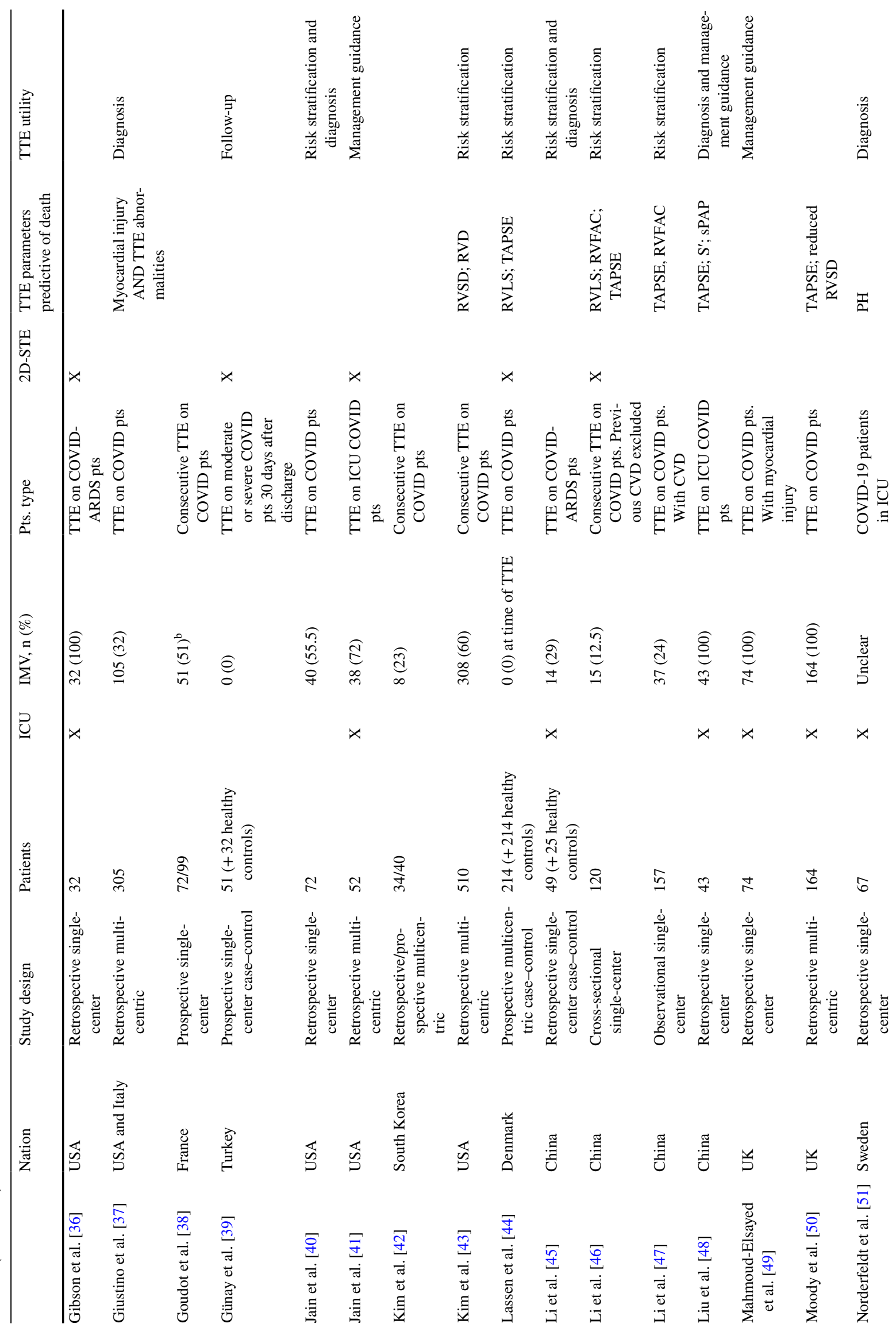




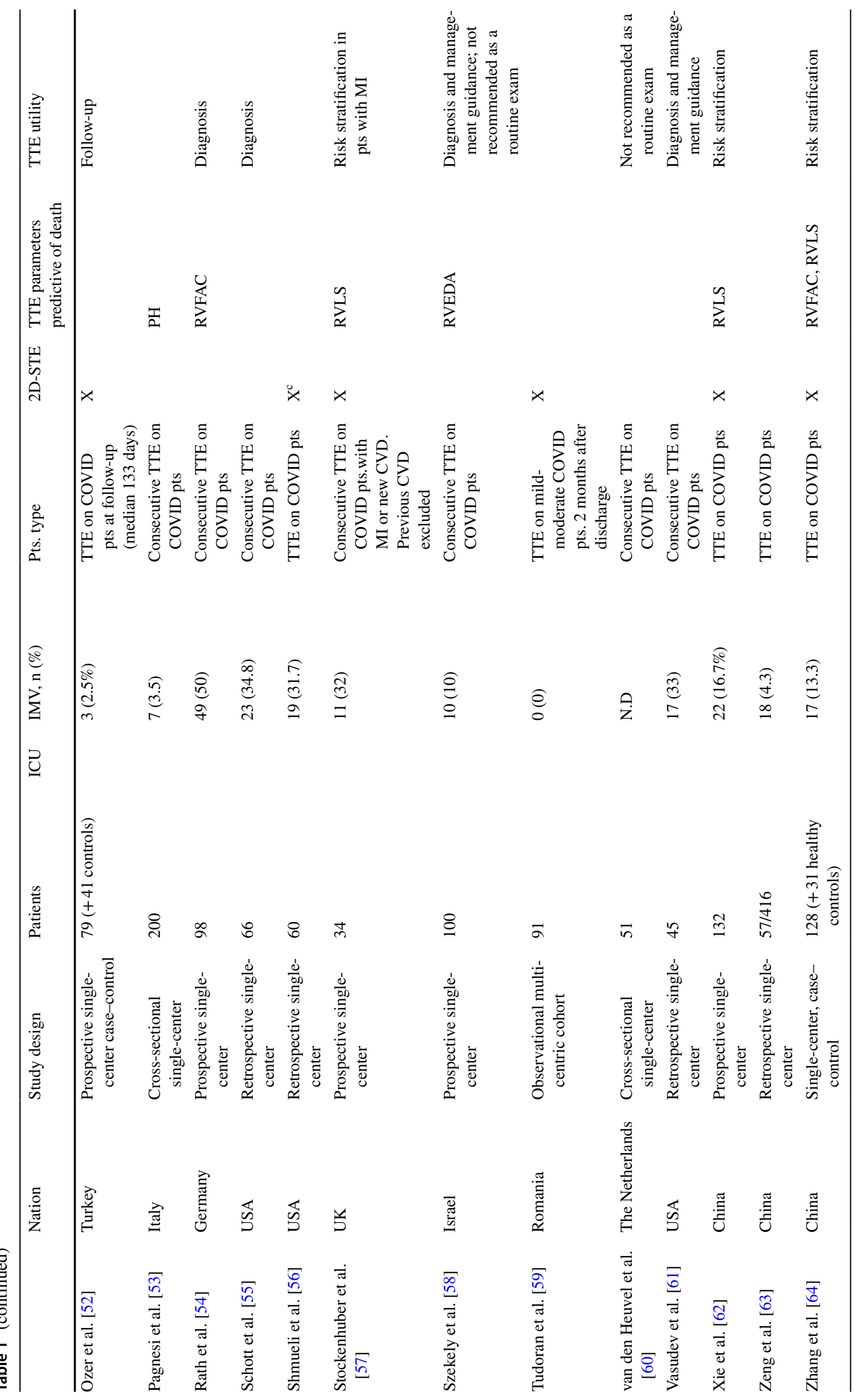




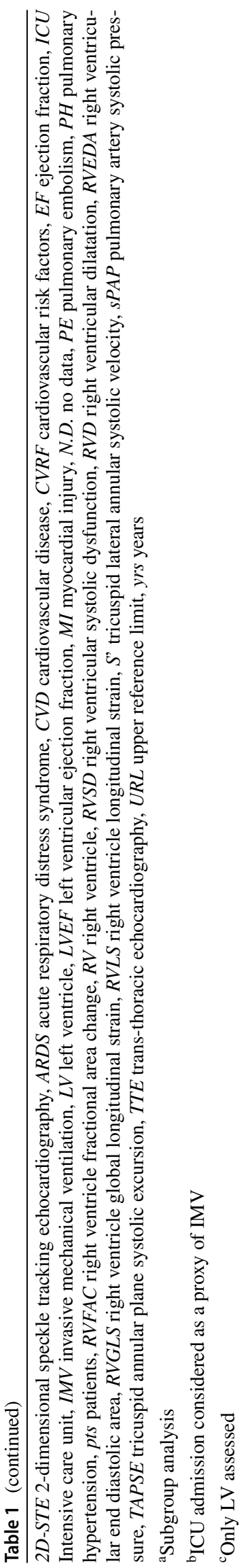

that RVEDD is increased in severe COVID-19 (as defined by the authors) [22, 23], in subjects with myocardial injury [22], and in those that did not survive to COVID-19 [48, 57]. In a small single-center study on patients without history of cardiovascular diseases (severe disease $n=40$, severe disease excluding IMV $n=22$ ), $L V$ end diastolic diameter and other parameters of right heart involvement (i.e. right atrial area, RVFAC) were significantly different when comparing severe and milder COVID-19 patients, suggesting that these alterations are independent of ventilatory support [22]. Similar evidence in a comparison between ventilated and non-ventilated COVID-related ARDS is reported [45].

Several studies assessed RV enlargement as a categorical variable with a binary cut-off of RVEDD, usually $41 \mathrm{~mm}$, according to consensus guidelines. [65] Kim et al. [43] showed that RV dilatation defined as RVEDD $>41 \mathrm{~mm}$ was more frequent than RV systolic dysfunction (evaluated through TAPSE and S'), and patients with RV dilatation had higher rates of ARDS and IMV. Of interest, RV dilatation (and also RV dysfunction) were associated with LV dysfunction. Cardiac involvement in this setting could be considered a consequence of RV afterload increase mediated by the exacerbation of the systemic inflammation rather than of pulmonary disease alone [66]. Given the RV and LV interdependence and the prolonged exposure to higher filling pressures [67], such critical systemic condition may influence hemodynamic and cause biventricular overload [48].

Results from a prospective study enrolling 100 consecutive hospitalized patients with COVID-19 showed that RV dilatation (with or without dysfunction) was present in $39 \%$ of subjects within $24 \mathrm{~h}$ of admission, whilst LV diastolic and systolic dysfunction were less frequently observed (respectively 16\% and 10\%).[58] Compared to Kim et al. [43], this study had a lower percentage of patients on IMV (10\%), possibly suggesting a less severe setting of COVID-19. Furthermore, the definition of RV dilatation by Szelkey et al. [58]. is dependent on a bidimensional measurement (RVEDA). Nevertheless, in both cohorts, RV dilatation was associated with an increased risk of death.

Finally, abnormal RV size has been reported also at post-acute follow-up. A case-control study with 51 patients with COVID-19 patients recovering from the acute illness without need of IMV reported higher RVEDA compared to controls at one month from hospital discharge [39]. Similar results were obtained in another study with follow up at a median time of $133 \pm 35$ days [52].

\section{Right ventricular systolic dysfunction}

There is great heterogeneity in the medical literature on COVID-19 about RV systolic function evaluation. The most used parameters are TAPSE, RVFAC and S'. Frequently, 


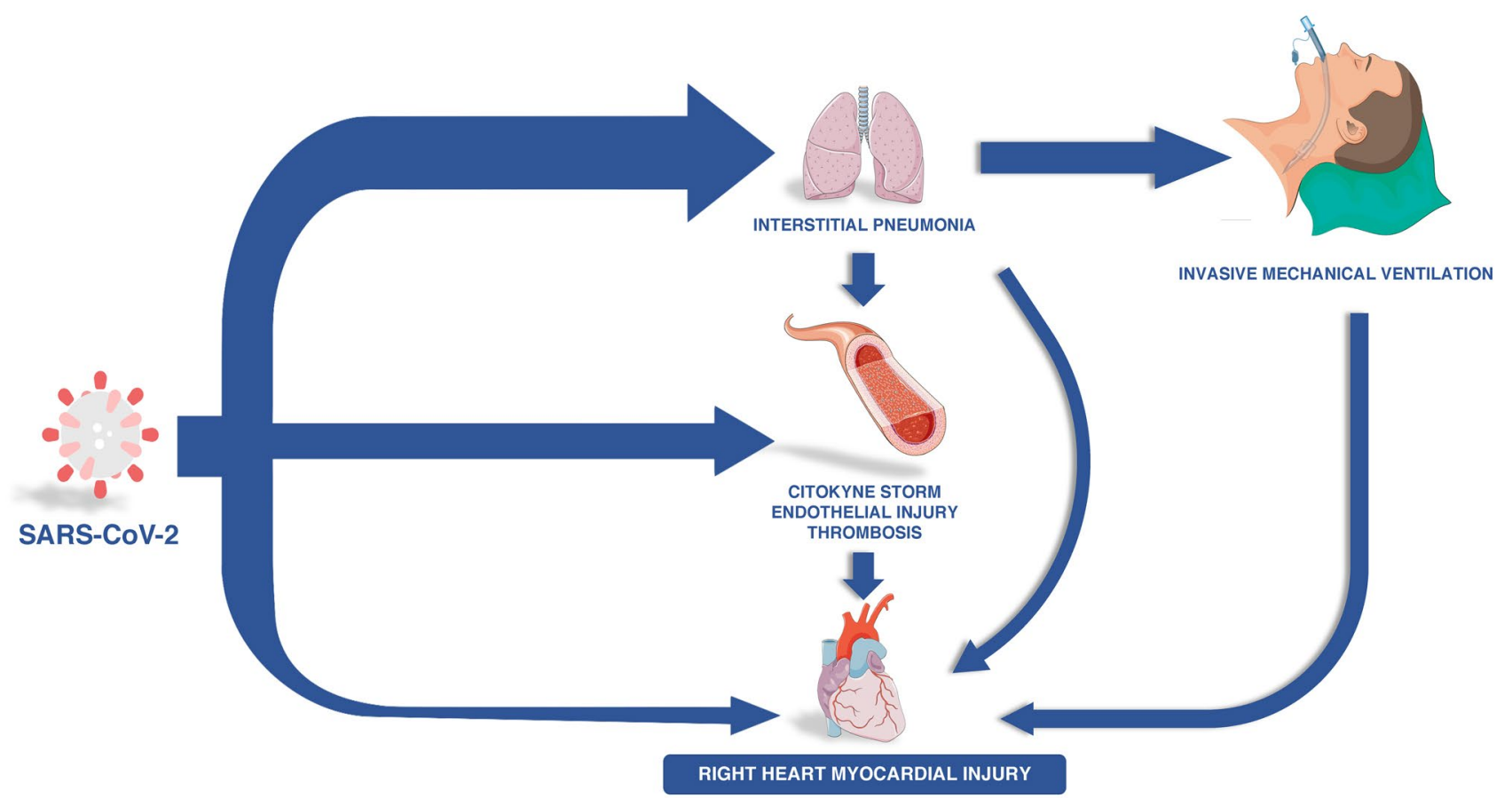

Fig. 2 Hypothesized mechanisms of right heart injury caused by COVID-19. Figure modified from Server Medical Art (licensed under a Creative Common Attribution 3.0 Generic License), Viktoriya

multiparametric evaluations combining these three measurements are used.

TAPSE is reported to be lower in patients with cardiac wall motion abnormalities [56] and critical illness [22, 45]. It appears to be lower in patients at 30-day follow-up after hospital discharge for COVID-19 compared to healthy volunteers [39] and in subjects with fatal outcome [28, 32, 46-48, 50, 57]. Moreover, a prospective case-control study showed that TAPSE was decreased in COVID-19 patients compared to healthy matched patients and low values of TAPSE were found to be independent risk factors for COVID-related death [44]. Authors hypothesized that their findings might be attributable to direct cardiac involvement or a sign of systemic extension of the viral disease. TAPSE was a good predictor of mortality both in samples with low $[46,47]$ and high [48] rates of intubated patients and showed correlation with D-dimer and increased cardiac troponins $[38,50]$.

Peak tricuspid annular longitudinal velocity $\left(\mathrm{S}^{\prime}\right)$ is usually assessed as a categorical variable with a $9.5 \mathrm{~cm}$ cut-off for RV dysfunction. It is reported to be lower in patients with myocardial injury[33, 60] and at risk for in-hospital mortality [48].

Similar to TAPSE and $\mathrm{S}^{\prime}$ wave, RVFAC appears to be lower in severe patients [22], in subjects at 30-day followup [39], and correlated to D-dimer [22, 49, 50]. If evaluated as a binary variable based on $35 \%$ cut-off for RV dysfunction, RVFAC has been shown to be predictive of mortality
Kabanova/Alamy Stock Photo, and from Desiree Ho for the innovative genomic institute

[47, 54]. Interestingly, in a study assessing RV dysfunction (TAPSE $<17 \mathrm{~mm}$ and/or RVFAC $<35 \%$ ), RVFAC-based dysfunction was found to be more frequent than TAPSEbased dysfunction [49], possibly explained by the marked reduction in radial RV systolic function but relative preservation of longitudinal shortening, as elucidated by another study [27]. The hypothesis is that TAPSE and $S^{\prime}$ operate a compensatory response to radial dysfunction. Moreover, RV free wall longitudinal function can appear falsely preserved due to tethering to a normally functioning LV which has increased or preserved function.

Many studies report data about RV dysfunction using a combination of the presented parameters. The results are dependent on the disease severity of the sample. For example, in a population with a median ratio of arterial oxygen partial pressure to fractional inspired oxygen $\left(\mathrm{Pa}_{\mathrm{O} 2} / \mathrm{Fi}_{\mathrm{O} 2}\right)$ of 243, RV dysfunction (based on TAPSE and $\mathrm{S}^{\prime}$ ) was not associated with $\mathrm{Pa}_{\mathrm{O} 2} / \mathrm{Fi}_{\mathrm{O} 2}$ and had no predictive power for mortality [53]. Conversely, RV dysfunction (based on TAPSE and RVFAC) was associated with $\mathrm{Pa}_{\mathrm{O} 2} / \mathrm{Fi}_{\mathrm{O} 2}$ and all-cause mortality in samples with higher rate of IMV patients (mean $\mathrm{Pa}_{\mathrm{O} 2} / \mathrm{Fi}_{\mathrm{O} 2}$ of 144) [50]. These results suggest that, during the initial stages of illness, TTE parameters of overt RV dysfunction may not be used as a valid predictor of mortality.

The correlation between troponin elevation and parameters of RV dysfunction has been evaluated [20, 22, 33, 47, 54]. A study including 305 subjects by Giustino et al.[37] 
identified myocardial injury as an independent risk factor for mortality, but only when major abnormalities were detected by TTE, particularly RV dysfunction $(26.3 \%$, determined by combination of visual assessment, TAPSE $<17 \mathrm{~mm}$, $\left.\mathrm{S}^{\prime}<9.5 \mathrm{~cm} / \mathrm{s}\right), \mathrm{LV}$ wall motion abnormalities $(23.7 \%)$, and LV global dysfunction (18.4\%).

Several works hypothesized different mechanisms of SARS-CoV-2 myocardial injury [3, 4, 68] (Fig. 2). The evidence of RV involvement presented in this review suggests that an increase in RV afterload, secondary to a multifactorial process, might play a role in this phenomenon. In adjunction to general causes involving the right heart similarly to the left chambers, the RV must sustain the additional burden of the respiratory illness due to SARS-CoV-2 infection. Right chambers tolerate preload augmentation worse than their left counterparts. Thus, high RV pressure produces RV myocardial stress and troponin release [69]. Increased levels of NT-ProBNP, the gold-standard biomarker of right and LV stretching in PH and/or heart failure, are commonly observed in COVID-19 patients [43, 47, 58].

\section{Pulmonary hypertension}

Pulmonary hypertension $(\mathrm{PH})$ is being increasingly reported among patients with COVID-19 [46, 66, 70, 71]. Its development is likely multifactorial and may be related to ventilation perfusion mismatch in the setting of significant hypoxic respiratory failure and acute respiratory distress syndrome, increased pulmonary vascular tone in the setting of inflammatory state, and presence of microthrombi or pulmonary embolism in the lungs [13, 27, 71, 72].

In standard echocardiography, estimated sPAP is widely used to define the presence of $\mathrm{PH}$, although guidelines recommend using the continuous wave Doppler measurement of peak TRV together with other sign of increased right heart overload as the unique variables for assigning the TTE probability of PH [73, 74]. However, many studies report sPAP as a valid parameter to assess COVID-19 severity, since it appears to be higher in severely ill patients [22, 23, 63], in subjects with previous cardiovascular diseases [41], and in those at higher risk of in-hospital mortality [32, 41, 46, 57]. Moreover, a direct correlation has been found between sPAP, D-dimer and troponin [38]. A study stratifying non-intensive care unit (ICU) patients according to presence/absence of $\mathrm{PH}$ (defined as sPAP $>35 \mathrm{mmHg}$ )[53] showed that, after adjustments for confounders, $\mathrm{PH}$ was the only significative predictive parameter of mortality. According to the authors, the initial hemodynamic alterations caused by SARS-CoV-2 pneumonia may determine only modest sPAP elevation, still not sufficient to induce significant RV dysfunction. However, COVID-19 is thought to alter the ventilation-to-perfusion ratio via a mismatch caused by capillary microthrombosis in some regions of the pulmonary vasculature. Such alterations of the pulmonary circulation may be the primary triggers causing involvement of right heart chambers [13, 75]. Analysing the impact of anticoagulation therapy (prophylactic or full-dose) on PH in patients with COVID-19 is cumbersome, since the majority of patients in the reported studies received anticoagulation [51]. Assessing whether echocardiography-directed use of higher doses of anticoagulation in these patients will reduce the rates of RV dysfunction and improve prognosis requires larger prospective studies [58].

The prognostic value of PH in the ICU setting was investigated in a study enrolling mainly intubated patients, where a $\mathrm{SPAP}>35 \mathrm{mmHg}$ increased the risk of in-hospital mortality after correction for confounders [34]. The incidence of $\mathrm{PH}$ varied among group of patients stratified by $\mathrm{Pa}_{\mathrm{O} 2} / \mathrm{Fi}_{\mathrm{O} 2}$. This suggests a different relationship in severe COVID-19 among RV preload and respiratory mechanics and might be partly caused by IMV. Positive end expiratory pressure causes an increase in pulmonary West zones 1 and 2 at the expense of zones 2 and 3, thus increasing pulmonary vascular resistance. Respiratory failure in COVID-19 leads to a large use of continuous positive airways pressure (C-PAP) and intubation: both cause important changes in thoracic pressures and thus in ventricular afterload [76, 77].

Finally, PH may represent a possible long-term complication of COVID-19. Tudoran et al. [59] performed TTE two months after discharge in patients that experienced mild/moderate pneumonia. They found 7 patients on a sample of $91(8 \%)$ with $\mathrm{PH}$, and 11 subjects (20\%) with sPAP $>30 \mathrm{mmHg}$ but $<35 \mathrm{mmHg}$. This prevalence of $\mathrm{PH}$ is higher compared to the general population [78]. Other studies found elevated sPAP and PH as a common COVID19 complication [39, 52], highlighting the need to further investigate long-term sequalae involving the RV after SARSCoV-2 infection.

\section{Right ventricular strain}

Right ventricular longitudinal strain (RVLS) is obtained from the apical four-chamber view, and it reflects the average value of the RV free wall and septal segments or of the RV free wall strain alone [79]. A meta-analysis suggested $-27 \pm 2 \%$ as the normal range [80], but an RVLS cutoff of $-20 \%$ to $-21 \%$ seems to be able to detect abnormal RV function [81]. RVLS calculated by two-dimensional speckle tracking echocardiography (2D-STE) proved to be a reliable and accurate tool for the evaluation of RV systolic function when validated against RVEF by CMR in several clinical settings, including $\mathrm{PH}$, pulmonary embolism, heart failure, myocardial infarction, cardiomyopathies, and valvular heart diseases [79, 82-84]. Moreover, impaired RVLS was associated with poor prognosis in inferior myocardial infarction [85], functional tricuspid regurgitation [86], and heart failure with preserved ejection fraction [87]. 
Table 2 Most used TTE parameters in RV assessment in COVID-19

\begin{tabular}{llll}
\hline & $\begin{array}{l}\text { Patients with } \\
\text { severe disease }\end{array}$ & $\begin{array}{l}\text { Patients with } \\
\text { myocardial } \\
\text { injury }\end{array}$ & $\begin{array}{l}\text { Predictor } \\
\text { of mor- } \\
\text { tality }\end{array}$ \\
\hline RVEDD & $\uparrow$ & $\uparrow$ & \\
$\quad$ RV dilatation & $\uparrow$ (frequency) & & $\mathrm{X}$ \\
TAPSE & $\downarrow$ & $\downarrow$ & $\mathrm{X}$ \\
RVFAC & & $\downarrow$ & $\mathrm{X}$ \\
S $^{\prime}$ & $\downarrow$ & $\downarrow$ & $\mathrm{X}$ \\
$\quad$ RV dysfunction & & $\uparrow$ (frequency) & $\mathrm{X}$ \\
sPAP & $\uparrow$ & $\uparrow$ & $\mathrm{X}$ \\
$\quad$ Pulmonary hyperten- & & & $\mathrm{X}$ \\
$\quad$ sion & & & \\
RVLS & $\downarrow$ & &
\end{tabular}

$I C U$ intensive care unit, $R V F A C$ right ventricle fractional area change, $R V$ right ventricle, $R V E D D$ right ventricular end diastolic diameter, $R V L S$ right ventricular longitudinal strain, $S^{\prime}$ tricuspid lateral annular systolic velocity, $S P A P$ systolic pulmonary artery pressure, TAPSE tricuspid annular plane systolic excursion

Currently, 2D-STE is not part of a standard TTE study, since it needs more time than a normal TTE exam and higher expertise, which explains the exiguity of studies reporting RV 2D-STE measurements in COVID-19. However, several works defend the advantages achieved through 2D-STE in RV functional evaluation.

RVLS appears to be reduced in COVID-19 if compared to controls [44] or to reference values [28] in two studies in which the percentage of intubated patients were respectively $0 \%$ and $15 \%$. Furthermore, similar evidence has been reported in studies describing the follow up of survivors [39, 52], where patients who experienced more severe pneumonia characterized by a more reliable decrease of RVLS.

Evidence of worse values of RVLS in patients with acute cor pulmonale, ${ }^{62}[24]$ severe COVID-19 ${ }^{21}$ [23] and in nonsurvivors[28, 46] has been reported. Predictive capacity of RVLS for all-cause-mortality has been demonstrated [23, 28, 46]. Among the studies presenting this evidence, the observational cross-sectional single-center cohort study by $\mathrm{Li}$ et al .[46] operated a stratification based on RVLS distribution by tertiles of 120 patients, $12.5 \%$ of whom were intubated. They identified higher values of D-dimer and C-Reactive Protein and higher frequency of high-flow-oxygen therapy and IMV in the less negative RVLS group. Furthermore, in the analysis of RVLS predictiveness the authors identified the cut-off value of $23 \%$ for recognizing the risk of mortality, with a sensitivity of $94.4 \%$ and specificity of $64.7 \%$. The independence of RVLS predictivity from LV parameters and the importance of RV strain to evaluate the severity of illness were presented as the major finding of the study. The authors operated a comparison with the conventional measurements of RV function, describing TAPSE and S' only as a partial representation of the RV contraction (since these define only RV free wall basal segment), and RVFAC having a great interobserver and intraobserver variability because of its dependence from imaging plane. The conclusions in terms of clinical utility of TTE were similar to Lassen et al. [44], suggesting TTE evaluation of RVLS as an important prognostic tool in patient stratification. Moreover, 2D-STE was independent from associated myocardial injury, as no significant difference was reported in troponin values levels among tertiles of RVLS.

\section{Discussion}

The results of this systematic review suggest that:

- RV size is larger in patients with more severe illness, and $\mathrm{RV}$ dilatation is a cardiac abnormality more frequent than LV or RV functional decline.

- Alteration of TAPSE, S' and RVFAC are frequent in patients with COVID-19 and are predictors of mortality, but relative preservation of longitudinal shortening in $\mathrm{RV}$ dysfunction indicate RVFAC as a more appropriate measure of global RV function.

- Elevated sPAP is present in COVID-19 and appears to be useful in early disease and in patients undergoing IMV. Furthermore, PH may play a role as a long-term complication.

- RVLS might be superior to 2-dimensional measurements to evaluate ventricular loss of function and predict adverse outcomes.

- Given the first evidence of long-term RV involvement after COVID-19, echocardiographic follow-up could be useful to stratify patients at higher risk of complications.

Table 2 summarizes the main evidence of the most used TTE parameters in RV assessment in COVID-19.

\section{Implications for clinical practice}

According to recommendations for right heart assessment, patients with COVID-19 should undergo echocardiography focused on the RV in order to exclude or confirm a right ventricular failure or overload, precise prognosis, stratify prognosis and optimize treatment [88].

In COVID-19, standard 4-chamber view can provide an accurate morphological and functional quantification of the right heart. However, RV size and function parameters measured from the RV-focused view are more reproducible than from 4-chamber acquisitions. Therefore, when clinical conditions allow the optimal acquisition of echocardiographic images, only the RV-focused view should be used for quantitative assessment of the RV [89]. 
RV contractility can be assessed through TAPSE, S', RVFAC and RVLS. TAPSE and S' can be regularly obtained in standard 4 chambers view and provide a reliable quantification of systolic function. The two latter normally need an optimal RV-focused view to be accurate. Compared to RVFAC, RV-strain is an advanced technique that is relatively angle-independent and possesses an improved signal-to-noise ratio. RVLS is still lacking normative data and requires additional validation. However, once a RV-focused view is available, RVLS provides a reliable global systolic functional assessment [90].

Patients with COVID-19 may develop pulmonary circulation disarrangement driven by vasoconstriction, pulmonary angiopathy, in-situ thrombosis, pulmonary embolisms, severe hypoxemia, and left heart dysfunction [91, 92]. An accurate echocardiography assessment of cardiopulmonary hemodynamics may guide the optimal treatment strategy beside providing a prognostic stratification.

Estimation of sPAP can result inaccurate in COVID-19 patients supported with non-invasive or IMV, since positive end-expiratory pressure influences RAP, which is added to right atrial-ventricular gradient obtained from tricuspid regurgitant jet velocity to calculate SPAP [27].

Table 3 summarizes the main parameters of echocardiographic RV assessment, their clinical meaning and technical feasibility.

\section{Limitations}

Some limitations should be considered when comparing the presented reports.

First, the majority of the studies included in the analysis are single center retrospective studies, with a small sample size. Hence, there is scarce homogeneity in all TTE examinations in terms of timing and choice of parameters. Second, the rate of TTE abnormalities in most studies cannot be considered representative of the population, as retrospective observational analyses only consider patients undergoing TTE to answer clinical questions, and even cross-sectional or prospective studies are not able to evaluate infected people not referring to the hospital. Third, many authors report difficulties in the execution of TTE exams, given the clinical risk of infection for examiners, the reduced quality of acoustic windows, along with the inability of patients to breathhold and position in the recombinant position. Thus, it may have influenced even the quality of the measurements and therefore could be considered a potential bias.

As the pandemic has been present for one year only, longterm sequelae regarding RV involvement or the development of cardiac dysfunction and/or heart failure are yet unknown and deserve further investigation. The findings presented in this review might be used to establish a TTE protocol to stratify patients and to early detect cardiac dysfunction that may need more focused care.

\section{Conclusions}

$\mathrm{RV}$ involvement is a frequent issue in COVID-19 and its features vary with the progression of illness. The pathogenesis of right heart damage is multifactorial and may be influenced by IMV. Echocardiographic assessment of the RV can be useful to stratify patients, to characterize myocardial injury, and to guide management in severe illness.

Table 3 Overview of the clinical meaning and technical feasibility of commonly used parameters of right ventricular assessment in echocardiography. Modified from Rudski et al. [90], Galiè et al. [73] and Lang et al. [65]

\begin{tabular}{|c|c|c|c|c|}
\hline Parameter & Reference values & Difficulty & Accuracy & Clinical meaning \\
\hline Basal RVEDD, mm & $25-41$ & Easy & Good & Pressure/volume overload \\
\hline TAPSE, mm & $\geq 17$ & Easy & Good & Longitudinal systolic function \\
\hline $\mathrm{S}^{\prime}, \mathrm{cm} / \mathrm{s}$ & $\geq 9.5$ & Easy & Good & Global systolic function \\
\hline RVFAC, $\%$ & $\geq 35$ & Moderate & Good & Global systolic function \\
\hline TR jet vel, $\mathrm{m} / \mathrm{s}$ & $<2.8$ & Easy & & Sign of pulmonary hypertension \\
\hline $\mathrm{RAP}, \mathrm{mmHg}$ & $0-5$ & Easy & Poor & Degree of circulatory compensation \\
\hline sPAP, $\mathrm{mmHg}$ & $<35$ & Easy & & Estimation of pulmonary circulation \\
\hline RVLS, \% & $\leq-20$ & Moderate-to-hard & Good & Global and regional systolic function \\
\hline
\end{tabular}

$R A P$ right atrial pressure, $R V F A C$ right ventricle fractional area change, $R V E D D$ right ventricular end diastolic diameter, $R V L S$ right ventricular global longitudinal strain, $S$ ' tricuspid lateral annular systolic velocity, $s P A P$ systolic pulmonary artery pressure, TAPSE tricuspid annular plane systolic excursion, $T R$ tricuspidal regurgitation 
Author contributions All authors were involved in manuscript drafting and critical revisions.

Funding The authors received no financial support for the research, authorship, and/or publication of this article.

\section{Declarations}

Conflict of interest All authors have no conflict of interest to disclose.

\section{References}

1. Shi S, Qin M, Shen B et al (2020) Association of cardiac injury with mortality in hospitalized patients with COVID-19 in Wuhan. China JAMA Cardiol. https://doi.org/10.1001/jamacardio.2020. 0950

2. Guo T, Fan Y, Chen M et al (2020) Cardiovascular implications of fatal outcomes of patients with coronavirus disease 2019 (COVID-19). JAMA Cardiol. https://doi.org/10.1001/jamacardio. 2020.1017

3. Tersalvi G, Vicenzi M, Calabretta D et al (2020) Elevated troponin in patients with coronavirus disease 2019: possible mechanisms. J Card Fail. https://doi.org/10.1016/j.cardfail.2020.04.009

4. Tersalvi G, Veronese G, Winterton D (2020) Emerging evidence of myocardial injury in COVID-19: a path through the smoke. Theranostics 10:9888-9889. https://doi.org/10.7150/thno.50788

5. Parohan M, Yaghoubi S, Seraji A (2020) Cardiac injury is associated with severe outcome and death in patients with Coronavirus disease 2019 (COVID-19) infection: a systematic review and meta-analysis of observational studies. Eur Heart J Acute Cardiovasc Care. https://doi.org/10.1177/2048872620937165

6. Stefanini GG, Chiarito M, Ferrante G et al (2020) Early detection of elevated cardiac biomarkers to optimise risk stratification in patients with COVID-19. Heart. https://doi.org/10.1136/heart jnl-2020-317322

7. Gao C, Gao C, Cai Y et al (2020) Association of hypertension and antihypertensive treatment with COVID-19 mortality: a retrospective observational study. Eur Heart J 41:2058-2066. https://doi. org/10.1093/eurheartj/ehaa433

8. Ruscica M, Macchi C, Iodice S et al (2021) Prognostic parameters of in-hospital mortality in COVID-19 patients-an Italian experience. Eur J Clin Invest. https://doi.org/10.1111/eci.13629

9. Argulian E, Sud K, Vogel B et al (2020) Right ventricular dilation in hospitalized patients with COVID-19 infection. JACC Cardiovasc Imaging 13:2459-2461. https://doi.org/10.1016/j.jcmg.2020. 05.010

10. Huang L, Zhao P, Tang D et al (2020) Cardiac involvement in patients recovered from COVID-2019 identified using magnetic resonance imaging. JACC Cardiovasc Imaging 13:2330-2339. https://doi.org/10.1016/j.jcmg.2020.05.004

11. Churchill TW, Bertrand PB, Bernard S et al (2020) Echocardiographic features of COVID-19 illness and association with cardiac biomarkers. J Am Soc Echocardiogr 33:1053-1054. https://doi. org/10.1016/j.echo.2020.05.028

12. Mahmoud-Elsayed HM, Moody WE, Bradlow WM et al (2020) Echocardiographic findings in patients with COVID-19 pneumonia. Can J Cardiol 36:1203-1207. https://doi.org/10.1016/j.cjca. 2020.05.030

13. Patel BV, Arachchillage DJ, Ridge CA et al (2020) Pulmonary angiopathy in severe COVID-19: physiologic, imaging, and hematologic observations. Am J Respir Crit Care Med 202:690-699. https://doi.org/10.1164/rccm.202004-1412OC
14. Repessé X, Charron C, Vieillard-Baron A (2015) Acute cor pulmonale in ARDS: rationale for protecting the right ventricle. Chest 147:259-265. https://doi.org/10.1378/chest.14-0877

15. Lok BY, Mukerjee D, Timms PM et al (2004) Natriuretic peptides, respiratory disease, and the right heart. Chest 126:1330-1336. https://doi.org/10.1378/chest.126.4.1330

16. Shor R, Rozenman Y, Bolshinsky A et al (2006) BNP in septic patients without systolic myocardial dysfunction. Eur J Intern Med 17:536-540. https://doi.org/10.1016/j.ejim.2006.07.013

17. Skulstad H, Cosyns B, Popescu BA et al (2020) COVID-19 pandemic and cardiac imaging: EACVI recommendations on precautions, indications, prioritization, and protection for patients and healthcare personnel. Eur Heart J Cardiovasc Imaging 21:592598. https://doi.org/10.1093/ehjci/jeaa072

18. Kirkpatrick JN, Mitchell C, Taub C et al (2020) ASE statement on protection of patients and echocardiography service providers during the 2019 novel coronavirus outbreak: endorsed by the American College of Cardiology. J Am Coll Cardiol 75:3078-3084. https://doi.org/10.1016/j.jacc.2020.04.002

19. Liberati A, Altman DG, Tetzlaff J et al (2009) The PRISMA statement for reporting systematic reviews and meta-analyses of studies that evaluate health care interventions: explanation and elaboration. PLoS Med 6:e1000100-e1000100. https://doi.org/10. 1371/journal.pmed.1000100

20. Arcari L, Luciani M, Cacciotti L et al (2020) Incidence and determinants of high-sensitivity troponin and natriuretic peptides elevation at admission in hospitalized COVID-19 pneumonia patients. Intern Emerg Med 15:1467-1476. https://doi.org/10. 1007/s11739-020-02498-7

21. Bagate F, Masi P, D'Humières T et al (2021) Advanced echocardiographic phenotyping of critically ill patients with coronavirus-19 sepsis: a prospective cohort study. J Intens Care 9:12. https://doi. org/10.1186/s40560-020-00516-6

22. Barman HA, Atici A, Tekin EA et al (2020) Echocardiographic features of patients with COVID-19 infection: a cross-sectional study. Int J Cardiovasc Imaging. https://doi.org/10.1007/ s10554-020-02051-9

23. Baycan OF, Barman HA, Atici A et al (2020) Evaluation of biventricular function in patients with COVID-19 using speckle tracking echocardiography. Int J Cardiovasc Imaging. https://doi.org/ 10.1007/s10554-020-01968-5

24. Beyls C, Bohbot Y, Huette P et al (2021) Usefulness of right ventricular longitudinal shortening fraction to detect right ventricular dysfunction in acute cor pulmonale related to COVID-19. J Cardiothorac Vasc Anesth. https://doi.org/10.1053/j.jvca.2021. 01.025

25. Bieber S, Kraechan A, Hellmuth JC et al (2021) Left and right ventricular dysfunction in patients with COVID-19-associated myocardial injury. Infection. https://doi.org/10.1007/ s15010-020-01572-8

26. Bitar ZI, Shamsah M, Bamasood OM et al (2021) Point-of-care ultrasound for COVID-19 pneumonia patients in the ICU. J Cardiovasc Imaging 29:60. https://doi.org/10.4250/jcvi.2020.0138

27. Bleakley C, Singh S, Garfield B et al (2021) Right ventricular dysfunction in critically ill COVID-19 ARDS. Int J Cardiol 327:251-258. https://doi.org/10.1016/j.ijcard.2020.11.043

28. Bursi F, Santangelo G, Sansalone D et al (2020) Prognostic utility of quantitative offline 2D-echocardiography in hospitalized patients with COVID-19 disease. Echocardiography. https://doi. org/10.1111/echo.14869

29. Busana M, Schiavone M, Lanfranchi A et al (2020) Non-invasive hemodynamic profile of early COVID-19 infection. Physiol Rep 8:e14628. https://doi.org/10.14814/phy2.14628

30. Chen LQ, Burdowski J, Marfatia R et al (2020) Reduced cardiac function is associated with cardiac injury and mortality risk in 
hospitalized COVID -19 patients. Clin Cardiol. https://doi.org/ $10.1002 / \mathrm{clc} .23479$

31. Crook RL, Williams H, Green M et al (2021) Prospective multicentre cohort study of transthoracic echocardiography provision in the South West of the UK during the first wave of SARS-CoV-2 pandemic. Open Heart 8:e01409. https://doi.org/10.1136/openh rt-2020-001409

32. D'Alto M, Marra AM, Severino S et al (2020) Right ventricular-arterial uncoupling independently predicts survival in COVID-19 ARDS. Crit Care 24:670. https://doi.org/10.1186/ s13054-020-03385-5

33. Doyen D, Dupland P, Morand L et al (2021) Characteristics of cardiac injury in critically Ill patients with coronavirus disease 2019. Chest 159:1974-1985. https://doi.org/10.1016/j.chest.2020. 10.056

34. García-Cruz E, Manzur-Sandoval D, Rascón-Sabido R et al (2020) Critical care ultrasonography during COVID-19 pandemic: the ORACLE protocol. Echocardiography (Mount Kisco, NY). https://doi.org/10.1111/echo.14837

35. García-Cruz E, Manzur-Sandoval D, Gopar-Nieto R et al (2020) Transthoracic echocardiography during prone position ventilation: lessons from the COVID-19 pandemic. J Am Coll Emerg Phys 1:730-736. https://doi.org/10.1002/emp2.12239

36. Gibson LE, Fenza RD, Lang $M$ et al (2021) Right ventricular strain is common in intubated COVID-19 patients and does not reflect severity of respiratory illness. J Intensive Care Med. https:// doi.org/10.1177/08850666211006335

37. Giustino G, Croft LB, Stefanini GG et al (2020) Characterization of myocardial injury in patients with COVID-19. J Am Coll Cardiol 76:2043-2055. https://doi.org/10.1016/j.jacc.2020.08.069

38. Goudot G, Chocron R, Augy JL et al (2020) Predictive factor for COVID-19 worsening: insights for high-sensitivity troponin and D-dimer and correlation with right ventricular afterload. Front Med 7:1-11. https://doi.org/10.3389/fmed.2020.586307

39. Günay N, Demiröz Ö, Kahyaoğlu M et al (2021) The effect of moderate and severe COVID-19 pneumonia on short-term right ventricular functions: a prospective observational single pandemic center analysis. Int J Cardiovasc Imaging. https://doi.org/10.1007/ s10554-021-02171-w

40. Jain SS, Liu Q, Raikhelkar J et al (2020) Indications for and findings on transthoracic echocardiography in COVID-19. J Am Soc Echocardiogr 33:1278-1284. https://doi.org/10.1016/j.echo.2020. 06.009

41. Jain R, Salinas PD, Kroboth S et al (2021) Comprehensive echocardiographic findings in critically Ill COVID-19 patients with or without prior cardiac disease. J Patient-Centered Res Rev 8:68-76. https://doi.org/10.17294/2330-0698.1791

42. Kim M, Nam J-H, Son J-W et al (2020) Cardiac manifestations of coronavirus disease 2019 (COVID-19): a multicenter cohort study. J Korean Med Sci 35:e366. https://doi.org/10.3346/jkms.2020.35. e366

43. Kim J, Volodarskiy A, Sultana R et al (2020) Prognostic utility of right ventricular remodeling over conventional risk stratification in patients with COVID-19. J Am Coll Cardiol 76:1965-1977. https://doi.org/10.1016/j.jacc.2020.08.066

44. Lassen MCH, Skaarup KG, Lind JN et al (2020) Echocardiographic abnormalities and predictors of mortality in hospitalized COVID-19 patients: the ECHOVID-19 study. ESC Heart Fail. https://doi.org/10.1002/ehf2.13044

45. Li Y-L, Zheng J-B, Jin Y et al (2020) Acute right ventricular dysfunction in severe COVID-19 pneumonia. Rev Cardiovasc Med 21:635. https://doi.org/10.31083/j.rcm.2020.04.159

46. $\mathrm{Li} \mathrm{Y}, \mathrm{Li} \mathrm{H}, \mathrm{Zhu} \mathrm{S}$ et al (2020) Prognostic value of right ventricular longitudinal strain in patients with COVID-19. JACC Cardiovasc Imaging. https://doi.org/10.1016/j.jcmg.2020.04.014
47. Li Y, Fang L, Zhu S et al (2021) Echocardiographic characteristics and outcome in patients with COVID-19 infection and underlying cardiovascular disease. Front Cardiovasc Med 8:642973-642973. https://doi.org/10.3389/fcvm.2021.642973

48. Liu Y, Xie J, Gao P et al (2020) Swollen heart in COVID-19 patients who progress to critical illness: a perspective from echocardiologists. ESC Heart Failure. https://doi.org/10.1002/ehf2. 12873

49. Mahmoud-Elsayed HM, Moody WE, Bradlow WM, Khan-Kheil AM, Senior J, Hudsmith LE, Steeds RP (2020) Echocardiographic findings in patients with COVID-19 pneumonia. Lancet 395:1315

50. Moody WE, Mahmoud-Elsayed HM, Senior J et al (2020) Impact of right ventricular dysfunction on mortality in patients hospitalized with COVID-19 according to race. CJC Open. https://doi.org/ 10.1016/j.cjco.2020.09.016

51. Norderfeldt J, Liliequist A, Frostell C et al (2021) Acute pulmonary hypertension and short-term outcomes in severe Covid-19 patients needing intensive care. Acta Anaesthesiol Scand. https:// doi.org/10.1111/aas.13819

52. Ozer PK, Govdeli EA, Baykiz D et al (2021) Impairment of right ventricular longitudinal strain associated with severity of pneumonia in patients recovered from COVID-19. Int J Cardiovasc Imaging. https://doi.org/10.1007/s10554-021-02214-2

53. Pagnesi M, Baldetti L, Beneduce A et al (2020) Integrated clinical role of echocardiography in patients with COVID-19. Heart 106:1864.2-1865. https://doi.org/10.1136/heartjnl-2020-318310

54. Rath D, Petersen-Uribe Á, Avdiu A et al (2020) Impaired cardiac function is associated with mortality in patients with acute COVID-19 infection. Clin Res Cardiol. https://doi.org/10.1007/ s00392-020-01683-0

55. Schott JP, Mertens AN, Bloomingdale R et al (2020) Transthoracic echocardiographic findings in patients admitted with SARSCoV-2 infection. Echocardiography. https://doi.org/10.1111/echo. 14835

56. Shmueli H, Shah M, Ebinger JE et al (2021) Left ventricular global longitudinal strain in identifying subclinical myocardial dysfunction among patients hospitalized with COVID-19. Int J Cardiol Heart Vasc 32:100719. https://doi.org/10.1016/j.ijcha. 2021.100719

57. Stockenhuber A, Vrettos A, Androschuck V et al (2021) A pilot study on right ventricular longitudinal strain as a predictor of outcome in COVID-19 patients with evidence of cardiac involvement. Echocardiography 38:222-229. https://doi.org/10.1111/ echo. 14966

58. Szekely Y, Lichter Y, Taieb P et al (2020) Spectrum of cardiac manifestations in COVID-19. Circulation 142:342-353. https:// doi.org/10.1161/CIRCULATIONAHA.120.047971

59. Tudoran C, Tudoran M, Lazureanu VE et al (2021) Evidence of pulmonary hypertension after SARS-CoV-2 infection in subjects without previous significant cardiovascular pathology. J Clin Med 10:199. https://doi.org/10.3390/jcm10020199

60. van den Heuvel FMA, Vos JL, Koop Y et al (2020) Cardiac function in relation to myocardial injury in hospitalised patients with COVID-19. Neth Heart J 28:410-417. https://doi.org/10.1007/ s12471-020-01458-2

61. Vasudev R, Guragai N, Habib H et al (2020) The utility of bedside echocardiography in critically ill COVID-19 patients: early observational findings from three Northern New Jersey hospitals. Echocardiography 37:1362-1365. https://doi.org/10.1111/echo. 14825

62. Xie Y, Wang L, Li M et al (2021) Biventricular longitudinal strain predict mortality in COVID-19 patients. Front Cardiovasc Med 7:632434. https://doi.org/10.3389/fcvm.2020.632434

63. Zeng JH, Wu WB, Qu JX et al (2020) Cardiac manifestations of COVID-19 in Shenzhen. China Infection 1:3. https://doi.org/10. 1007/s15010-020-01473-w 
64. Zhang Y, Sun W, Wu C et al (2021) Prognostic value of right ventricular ejection fraction assessed by $3 \mathrm{D}$ echocardiography in COVID-19 patients. Front Cardiovasc Med 8:641088. https://doi. org/10.3389/fcvm.2021.641088

65. Lang RM, Badano LP, Mor-Avi V et al (2015) Recommendations for cardiac chamber quantification by echocardiography in adults: an update from the American Society of Echocardiography and the European Association of Cardiovascular Imaging. Eur Heart J 16:233-271. https://doi.org/10.1093/ehjci/jev014

66. Deng Q, Hu B, Zhang Y et al (2020) Suspected myocardial injury in patients with COVID-19: evidence from front-line clinical observation in Wuhan, China. Int J Cardiol. https://doi.org/10. 1016/j.ijcard.2020.03.087

67. Naeije R, Badagliacca R (2017) The overloaded right heart and ventricular interdependence. Cardiovasc Res 113:1474-1485. https://doi.org/10.1093/cvr/cvx160

68. Imazio M, Klingel K, Kindermann I et al (2020) COVID-19 pandemic and troponin: indirect myocardial injury, myocardial inflammation or myocarditis? Heart (British Cardiac Society). https://doi.org/10.1136/heartjnl-2020-317186

69. Stefanini GG, Montorfano M, Trabattoni D et al (2020) ST-elevation myocardial infarction in patients with COVID-19: clinical and angiographic outcomes. Circulation 141:2113-2116. https:// doi.org/10.1161/CIRCULATIONAHA.120.047525

70. Mishra A, Lal A, Sahu KK et al (2020) An update on pulmonary hypertension in coronavirus disease-19 (COVID-19): pulmonary Hypertension and COVID -19. Acta Biomedica Atenei Parmensis 91:e2020155. https://doi.org/10.23750/abm.v91i4.10698

71. Wats K, Rodriguez D, Prins KW et al (2021) Association of right ventricular dysfunction and pulmonary hypertension with adverse 30-day outcomes in COVID-19 patients. Pulm Circ 11:204589402110070. https://doi.org/10.1177/204589402110070 40

72. Ackermann M, Verleden SE, Kuehnel M et al (2020) Pulmonary vascular endothelialitis, thrombosis, and angiogenesis in Covid19. N Engl J Med 383:120-128. https://doi.org/10.1056/NEJMo a2015432

73. Galiè N, Humbert M, Vachiery JL et al (2016) 2015 ESC/ERS Guidelines for the diagnosis and treatment of pulmonary hypertension. Eur Heart J 37:67-119. https://doi.org/10.1093/eurheartj/ ehv317

74. Otto CM (2018) Textbook of clinical echocardiography, 6th edn. Elsevier, Philadelphia

75. Siddiqi HK, Mehra MR (2020) COVID-19 illness in native and immunosuppressed states: a clinical-therapeutic staging proposal. Elsevier, New York

76. Bone RC (1982) Complications of mechanical ventilation and positive end-expiratory pressure. Respir Care 27:402-407

77. Vieillard-Baron A, Loubieres Y, Schmitt JM et al (1999) Cyclic changes in right ventricular output impedance during mechanical ventilation. J Appl Physiol 87:1644-1650. https://doi.org/10.1152/ jappl.1999.87.5.1644

78. Moreira EM, Gall H, Leening MJG et al (2015) Prevalence of pulmonary hypertension in the general population: the Rotterdam Study. PLoS ONE 10:e0130072. https://doi.org/10.1371/journal. pone. 0130072

79. Longobardo L, Suma V, Jain R et al (2017) Role of two-dimensional speckle-tracking echocardiography strain in the assessment of right ventricular systolic function and comparison with conventional parameters. J Am Soc Echocardiogr 30:937-946.e6. https:// doi.org/10.1016/j.echo.2017.06.016
80. Fine NM, Chen L, Bastiansen PM et al (2015) Reference values for right ventricular strain in patients without cardiopulmonary disease: a prospective evaluation and meta-analysis. Echocardiography 32:787-796. https://doi.org/10.1111/echo.12806

81. Lang RM, Badano LP, Mor-Avi V et al (2015) Recommendations for cardiac chamber quantification by echocardiography in adults: an update from the American Society of Echocardiography and the European Association of Cardiovascular Imaging. J Am Soc Echocardiogr 28:1-39.e14. https://doi.org/10.1016/j.echo.2014. 10.003

82. Wang J, Prakasa K, Bomma C et al (2007) Comparison of novel echocardiographic parameters of right ventricular function with ejection fraction by cardiac magnetic resonance. J Am Soc Echocardiogr 20:1058-1064. https://doi.org/10.1016/j.echo.2007. 01.038

83. Vizzardi E, Bonadei I, Sciatti E et al (2015) Quantitative analysis of right ventricular (RV) Function with echocardiography in chronic heart failure with no or mild RV dysfunction: comparison with cardiac magnetic resonance imaging. J Ultrasound Med 34:247-255. https://doi.org/10.7863/ultra.34.2.247

84. Focardi M, Cameli M, Carbone SF et al (2015) Traditional and innovative echocardiographic parameters for the analysis of right ventricular performance in comparison with cardiac magnetic resonance. Eur Heart J 16:47-52. https://doi.org/10.1093/ehjci/ jeu156

85. Park SJ, Park J-H, Lee HS et al (2015) Impaired RV global longitudinal strain is associated with poor long-term clinical outcomes in patients with acute inferior STEMI. JACC Cardiovasc Imaging 8:161-169. https://doi.org/10.1016/j.jcmg.2014.10.011

86. Prihadi EA, van der Bijl P, Dietz M et al (2019) Prognostic implications of right ventricular free wall longitudinal strain in patients with significant functional tricuspid regurgitation. Circ Cardiovasc Imaging. https://doi.org/10.1161/CIRCIMAGING.118.008666

87. Lejeune S, Roy C, Ciocea V et al (2020) Right ventricular global longitudinal strain and outcomes in heart failure with preserved ejection fraction. J Am Soc Echocardiogr 33:973-984.e2. https:// doi.org/10.1016/j.echo.2020.02.016

88. Peng Q-Y, Wang X-T, Zhang L-N, Chinese Critical Care Ultrasound Study Group (CCUSG) (2020) Using echocardiography to guide the treatment of novel coronavirus pneumonia. Crit Care 24:143. https://doi.org/10.1186/s13054-020-02856-z

89. Genovese D, Mor-Avi V, Palermo C et al (2019) Comparison between four-chamber and right ventricular-focused views for the quantitative evaluation of right ventricular size and function. J Am Soc Echocardiogr 32:484-494. https://doi.org/10.1016/j. echo.2018.11.014

90. Rudski LG, Lai WW, Afilalo J et al (2010) Guidelines for the echocardiographic assessment of the right heart in adults: a report from the American Society of Echocardiography. J Am Soc Echocardiogr 23:685-713. https://doi.org/10.1016/j.echo.2010. 05.010

91. Gupta A, Madhavan MV, Sehgal K et al (2020) Extrapulmonary manifestations of COVID-19. Nat Med 26:1017-1032. https://doi. org/10.1038/s41591-020-0968-3

92. Giustino G, Pinney SP, Lala A et al (2020) Coronavirus and cardiovascular disease, myocardial injury, and arrhythmia: JACC focus seminar. J Am Coll Cardiol 76:2011-2023. https://doi.org/ 10.1016/j.jacc.2020.08.059

Publisher's Note Springer Nature remains neutral with regard to jurisdictional claims in published maps and institutional affiliations. 